\title{
Qualidade de frutos de cultivares de mamão comercializados em supermercados de Campina Grande-PB ${ }^{1}$
}

\author{
Talita de Farias Sousa Barros ${ }^{2}$, Elica Santos Carvalho Rios ${ }^{3}$, Leonardo Dantas Marques \\ Maia $^{4}$, Renato Lima Dantas ${ }^{5}$, Silvanda de Melo Silva ${ }^{6}$
}

\begin{abstract}
Resumo: O mamão é bastante consumido no Brasil, sendo comercializado de diferentes formas, resultando na modificação da sua qualidade. Visando obter informações sobre a qualidade dos frutos comercializados localmente, é necessário avaliar os atributos de qualidade levados em consideração pelos consumidores. Diante disso, objetivou-se avaliar a qualidade pós-colheita de mamões das cultivares Havaí e Formosa, comercializados em diferentes estabelecimentos de Campina Grande, Paraíba. Os dados foram levantados através da aplicação de questionários para clientes e gerentes dos estabelecimentos, bem como pela coleta periódica e avaliação de amostras. A avaliação da qualidade foi realizada em 6 supermercados, três de grande e três de médio porte, segundo as condições de varejo. Foram avaliadas 8 triplicatas frutos por supermercado/coleta quanto aos atributos físicoquímicos e sensoriais. Também foi avaliado a incidência de antracnose, podridão peduncular e pinta preta durante 5 dias. O mamão 'Havaí' é o preferido pelos clientes, com base no tamanho. A logística de compra e venda, transporte inadequado e manipulação dos frutos pelos clientes são as maiores causas das perdas. O mamão 'Havaí' apresentou maior incidência de antracnose e podridão peduncular e o 'Formosa' de pinta preta em supermercados de grande porte.
\end{abstract}

Palavras-chave: Carica papaya L.; Comercialização no varejo; Patógenos fúngicos; Perdas pós-colheita.

\section{Quality of papaya cultivars fruits commercialized in supermarkets from Campina Grande, state of Paraíba}

\begin{abstract}
Papaya is widely consumed in Brazil, being marketed in different ways, leading to the modification of fruit quality. In order to obtain information about the quality of locally available fruits, it is necessary to assess the quality attributes considered by the consumers. The aim of this study was to characterize, quantify and evaluate the post-harvest quality of papaya of the cultivars Hawaii and Formosa, marketed in different supermarkets in Campina Grande, Paraíba. Data were collected through the application of questionnaires to customers and supermarket managers, as well the periodic collection and evaluation of fruit samples. The quality evaluation was carried out in three large and three medium-sized supermarkets, according to the retail conditions. Triplicates of 8 fruits per supermarket/collection were evaluated for physicochemical and sensorial attributes. It was also evaluated the incidence of anthracnose, stalk rot and black spot during 5 days. 'Hawaii' papaya is preferred based on size. The logistics of buying and selling, inadequate transport, and handling of fruits by customers are the major causes of losses. 'Hawaii' papaya presented a higher incidence of anthracnose and stalk rot and the 'Formosa' of black spot in large supermarkets.
\end{abstract}

Key words: Carica papaya L.; Fungal pathogens; Postharvest; Retail marketing.

\footnotetext{
${ }^{1}$ Submetido em 06/03/2018 e aprovado em 16/05/2018

${ }^{2}$ Doutora em Agronomia; Universidade Federal da Paraíba (UFPB), Centro de Ciências Agrária, Areia - Paraíba, CEP: 58397-000; E-mail: talita_ufpb@hotmail.com,

${ }^{3}$ Doutora em Agronomia; Universidade Federal da Paraíba (UFPB), Centro de Ciências Agrária, Areia - Paraíba, CEP: 58397-000; E-mail: 1k.rios@hotmail.com

${ }^{4}$ Doutor em Agronomia; Universidade Federal da Paraíba (UFPB), Centro de Ciências Agrária, Areia - Paraíba, CEP: 58397-000; E-mail: ldtecnologo@gmail.com

${ }^{5}$ Doutor em Agronomia; Professor, Faculdades Nova Esperança, João Pessoa - Paraíba, CEP: 58067-698; E-mail: renato_dantas@hotmail.com.br

${ }^{6}$ Doutora em Agronomia; Professora, Universidade Federal da Paraíba (UFPB), Centro de Ciências Agrária, Areia - Paraíba, CEP: 58397-000; E-mail: silvasil@cca.ufpb.br
} 


\section{Introdução}

O consumo de frutos e hortaliças tem aumentado em decorrências das fortes evidências dos vários efeitos benéficos para a saúde humana (Rupasinghe e $\mathrm{Yu}, 2013$ ). Neste contexto, o mamão é rico em vitaminas $\mathrm{A}, \mathrm{C}$ e em antioxidantes. Entretanto, é também um fruto climatérico altamente perecível e sujeito a elevadas perdas pós-colheita (Pan et al., 2017). Este fruto é de amplo consumo e importância comercial, estando entre os com maior produção no Brasil, com 1.424.650 ton. em 2016 (FAO, 2017). Em 2015, o Nordeste contribuiu com $60,44 \%$ da produção de mamão do país colhendo 917.380 ton, ocupando o $1^{\circ}$ lugar no ranking nacional e a Paraíba o $7^{\circ}$ lugar tendo colhido 40.340 ton. (IBGE, 2017).

Os tipos mais cultivados no território Brasileiro pertencem aos grupos Solos e Formosa. Os do grupo Solo, com frutos pequenos e de polpa avermelhada, são os preferidos para a exportação. Frutos do grupo Formosa, de tamanho médio e polpa laranja-avermelhada, são híbridos comercias que vêm ganhando espaço nos mercados interno e externo (Reis et al., 2015). No entanto, mamões são susceptíveis a doenças, como a mancha anelar, varíola (pinta preta), podridão peduncular e a antracnose, que podem restringir o mercado de fruto fresco comprometendo a sustentabilidade da cultura (Oliveira et al., 2011).

O mamão é um fruto bastante nutritivo e com boas qualidades organolépticas, possui uma boa aceitação no mercado consumidor. Entretanto, é necessário que se tenha adequadas condições de cultivo, colheita na época correta e no estádio de maturação apropriado, para a obtenção de frutos com qualidade, além disso, um bom manuseio na cadeia pós-colheita se faz necessário para manutenção desta qualidade (Fagundes e Yamanishi, 2001).

Os atributos de qualidade incluem aspectos de aparência, textura, sabor, além do nutricional e da segurança. Os fatores de aparência incluem tamanho, forma, cor e ausência de defeitos e deterioração. A textura, por sua vez inclui firmeza, frescura e suculência. O componente de sabor abrange a doçura, acidez, adstringência, amargor, aroma e sabor anormal. $\mathrm{O}$ aspecto de segurança, que inclui a ausência de resíduos de pesticidas, micotoxinas produzidas por certos fungos, presença de metais pesados e contaminação microbiana constitui também um importante ponto que influencia a qualidade de frutas (Prasad et al., 2018). Para as diferentes variedades de mamoeiro, torna-se um grande desafio a manutenção desses atributos, sobretudo a textura e a aparência.

Nesse contexto, o manuseio inadequado é apontado como principal causa dos elevados índices de perdas pós-colheita, sendo os danos mecânicos provocados pelo transporte também causadores da redução na qualidade dos frutos, causando danos na aparência e incidência de podridões (Aujla et al., 2011; Prusky, 2011).

Assim, o conhecimento dos fatores que compõem o sistema de comercialização é de fundamental importância, para que sejam adotadas tecnologias visando a redução das perdas pós-colheita (Parfitt et al., 2010) e de novos métodos de armazenamento, manuseio e apresentação dos frutos para o mercado consumidor. Diante disso, objetivou-se avaliar a qualidade pós-colheita de mamões das cultivares Havaí e Formosa, comercializados em diferentes estabelecimentos de Campina Grande, Paraíba.

\section{Material e Métodos}

Os frutos das cultivares de mamoeiro Havaí e Formosa (Carica papaya L.) foram coletados nos meses de setembro a dezembro de 2014, em 6 supermercados da cidade de Campina Grande$\mathrm{PB}$, selecionados segundo as condições de oferta no varejo (E1, E3 e E4), estabelecimentos de grande porte, nos quais os frutos eram mantidos sob refrigeração, e aos E2, E5 e E6, de médio porte, com frutos mantidos sob a condição ambiente). De cada estabelecimento foram coletados aleatoriamente, durante 6 semanas (duas coletas em cada mês avaliado, na primeira e última semana do mês por apresentar maior movimento de consumidores nos supermercados), amostras de 30 frutos por cultivar para análises sensoriais de qualidade e fitossanitárias, realizadas no Centro de Ciências Agrárias da UFPB, Areia-PB.

Nos supermercados foram aplicados questionários aos clientes, gerentes e uma avaliação do ambiente de comercialização foi realizada em cada coleta. A aplicação do questionário aos gerentes foi realizada no primeiro contato em cada supermercado, sendo

Revista Agropecuária Técnica, Areia-PB, v. 39, n. 2, p. 129-142, 2018

DOI: https://doi.org/ 10.25066/agrotec.v39i2.38109 
formuladas questões em relação aos tipos das cultivares comercializadas, a preferência dos consumidores, os fornecedores dos frutos, o local de origem destes, os dias da semana que eram recebidos, os critérios de seleção para o descarte, a quantidade de funcionários responsáveis pelo o setor, se a qualidade do fruto variava em relação à época do ano e, a respeito dos critérios para determinação do valor do produto para o cliente.

Em cada estabelecimento foram entrevistados 90 clientes sobre o que pensam a respeito da qualidade do mamão (boa qualidade ou a qualidade varia no decorrer do ano); qual cultivar tem mais costume de comprar: Havaí, Formosa, as duas; do critério de preferência (maior vida útil, mais saboroso e pelo tamanho) e principal fator da escolha das cultivares (coloração, preço, sem manchas e tamanho). Durante as avaliações realizadas em cada supermercado eram observadas à forma de exposição, uniformidade, aparência e embalagem dos frutos, bem como a variação do preço durante o período de coleta.

A análise sensorial foi realizada utilizando uma escala de notas de 0-10, com 16 avaliadores treinados pela equipe do Laboratório de Biologia e Tecnologia Pós-colheita da Universidade Federal da Paraíba, sendo considerados os atributos de qualidade: cor, brilho, manchas escuras, desidratação e intenção de compras. De cada cultivar foram avaliados, através de percepção visual, 24 frutos íntegros divididos em 4 grupos, os mesmos foram dispostos em bancadas. Na escala a nota 0 indica ausência de atributos de qualidade (sendo uma característica ruim para os parâmetros de cor e brilho, mas uma característica favorável para manchas escuras, desidratação e podridão), 5 regular e 10 presença máxima dos atributos. No atributo de intenção de compras 0 significa rejeitado, 5 aceito com restrições e 10 aceito.

Foram avaliados, 24 frutos quanto à massa fresca $(\mathrm{g})$, comprimento $(\mathrm{mm})$ e diâmetro $(\mathrm{mm})$ com paquímetro, firmeza determinada em dois pontos distintos da região mediana dos frutos, com penetrômetro Magness Taylor Pressure Tester (Drill Press Stand, Canada), com ponta de 2/16 polegadas, inserção de $6 \mathrm{~mm}$; rendimento da polpa, através das pesagens em balança semianalítica; coloração da casca e da polpa, através de calorímetro digital portátil Minolta, expressa nos parâmetros: L*; $\mathrm{a}^{*} \mathrm{e} \mathrm{b}^{*}$, o que correspondeu a 24 repetições por avaliação. $O$ conteúdo de solúveis - SS (\%), determinados com refratômetro digital (Kruss-optronic, Hamburgo, Alemanha); Acidez titulável - AT (\% ácido cítrico), determinada por titulação do suco com solução de $\mathrm{NaOH}$ a $0,1 \mathrm{M}$; Relação SS/AT, relação entre os teores de SS e de AT; $\mathrm{pH}$, determinado no suco, com potenciômetro digital (Hanna, Singapura), todos conforme a AOAC (2005), em triplicata, em 8 repetições, sendo que cada coleta foi considerada uma repetição.

Nas avaliações de sanidade, os frutos foram acondicionados ao ambiente sendo realizadas, as avaliações referentes à severidade da antracnose, podridão peduncular e pinta preta, doenças de impacto na pós-colheita do mamão em 6 frutos, por meio de julgadores previamente treinados. Utilizou-se um delineamento inteiramente casualizado em esquema de parcela subdividida no tempo (supermercado $\mathrm{x}$ tempo). A severidade da antracnose e da podridão peduncular foram realizadas diariamente. Para a antracnose utilizou escala de aparência, em que: $0=0 \% ; 1=0,1$ a $12,5 \% ; 2=12,6$ a $25 \% ; 3=25,1$ a $50 \%$ e $4=$ $>50,1 \%$ da face mais lesionada do fruto (Tatagiba et al., 2002). Para a podridão peduncular utilizouse escala de nota, segundo Nery-Silva et al. (2007), em que: 1 - ausência de sintomas da podridão peduncular; 2 - presença de pequenas pontuações aquosas superficiais na região do pedúnculo; 3 - presença de lesões aquosas ou mumificadas, abrangendo maior área em torno do pedúnculo; 4 - presença de lesões coalescentes, com aspecto translúcido ou mumificado, limitando-se à região peduncular e 5 - lesões semelhantes às descritas para a nota 3, abrangendo maior extensão do fruto. A avaliação da pinta-preta foi realizada no momento da aquisição dos frutos utilizando a escala diagramática de Vivas et al. (2010), cujos níveis equivalem a 0,$1 ; 0,3 ; 0,6 ; 1,2 ; 2,5 ; 5,0 ; 10,0 \mathrm{e}$ $20,0 \%$ da superfície lesionada.

Os dados descritivos foram submetidos à análise de Box-plot, os demais dados referentes à qualidade pós-colheita, foram submetidos à análise de variância, pelo teste $\mathrm{F}(\mathrm{p} \leq 0,05)$ e para avaliações de sanidades foi aplicado o teste de Tukey $(p \leq 0,05)$, utilizando o software SAS $^{\circledR}$. Adicionalmente, foi realizada Análise de Componentes Principais (ACP) para as variáveis dos frutos de mamoeiro 'Formosa' e 'Havaí' comercializados em diferentes supermercados da cidade de Campina Grande - PB. O número de 
componentes principais foi baseado na variância acumulada $\approx 70$.

\section{Resultados e Discussão}

A Figura 1 apresenta a média, desvio padrão e valores máximos e mínimos sobre a opinião dos clientes a respeito da qualidade do mamão: é de boa qualidade (Figura 1A), a qualidade varia com a época do ano (Figura 1B); qual cultivar tem mais costume de comprar: Havaí (Figura 1C), Formosa (Figura 1D), as duas (Figura 1E); principal critério de preferência: mais saboroso (Figura 1F), maior vida útil (Figura 1G), pelo tamanho (Figura $1 \mathrm{H}$ ); principal fator da escolha das cultivares: coloração (Figura 1I), preço (Figura 1J), sem manchas (Figura 1L), tamanho (Figura 1M), comercializadas nos supermercados de médio e grande porte da cidade de Campina Grande.

Entre os consumidores de mamão entrevistados, independentemente de ser da cultivar Formosa ou Havaí, notou-se que o mamão comercializado nos supermercados de médio porte (E2 e E6) são de boa qualidade (Figura 1A). As menores médias 58 e $54 \%$ foram dos supermercados de grande porte E3 e E4, para os quais também foram apontadas as maiores variações de qualidade $(42$ e $46 \%$, respectivamente) nos mamões comercializados (Figura 1B).

Segundo os clientes e gerentes, a qualidade do mamão varia a depender da época do ano, sendo nos períodos chuvosos o mamão é considerado de qualidade inferior. No supermercado E4, o fluxo de pessoas no setor de hortifrutigranjeiro era intenso, entretanto, nem todos compravam com o argumento de que os preços eram acima da média e por isso, preferiam outros estabelecimentos com preços mais acessíveis. Assim, de acordo com os gerentes, em alguns períodos os frutos ficavam expostos por maior tempo, e o manuseio excessivo dos clientes, favorecia a diminuição da qualidade.

No geral, os gerentes dos estabelecimentos informaram que os descartes de frutos ou a baixa qualidade dos mesmos são provocados pela excessiva manipulação do cliente no momento da compra, causando amassamento e ferimentos; podridões causadas por doenças; colheita na maturidade inadequada, deficiência no transporte e, principalmente $(56 \%)$, a demora na logística de entre a compra e venda, nos de grande porte. Os supermercados de médio e grande porte de Campina Grande, 25 e 33,3\%, respectivamente, atribuíram às perdas ao manuseio dos clientes, armazenamento inadequado e qualidade inferior do fruto comprado. Panorama similar foi descrito por Fagundes e Yamanishi (2002) em mamão de diferentes equipamentos varejistas em Brasília, $72,4 \%$ dos varejistas entrevistados citaram que os motivos causadores de perdas são decorrentes da qualidade inferior do fruto adquirido, manipulação excessiva do cliente, preços elevados, más condições de transporte, demora entre compra e venda, do excedente de oferta e das condições climáticas.

De acordo com os gerentes, as distribuidoras de mamões para os supermercados estão em locais afastados do centro de comercialização. Os supermercados E1 e E5 compram frutos do município de Mamanguape, litoral da Paraíba; o E2 e E4 de Recife e E6 da Bahia. Como estratégia para minimizar os danos no transporte, os mamões são entregues pelos fornecedores em caixa plásticas nos supermercados E2, E5 e E6 (médio porte), e em caixa de papelão identificada no E1. Nos E3 e E4 o mamão era fornecido nos dois tipos de caixas que são consideradas apropriadas para minimizar as perdas, além de proteger, facilitar o transporte e melhorar a aparência dos frutos.

A caixa de madeira foi abolida por todos os estabelecimentos devido aos danos. Para tentar manter a qualidade dos frutos na recepção, os supermercados E1 e E3 (grande porte) e E5 (médio porte), monitoram o descarregamento dos frutos pelos fornecedores. Nos supermercados E2, E4 e E6 o descarregamento é realizado pelos próprios funcionários, além disso, os frutos são embalados individualmente com redes de poliestireno que minimizam os impactos, servem de proteção e agregam valor. Nos setores de recepção de frutos há funcionários encarregados pela organização e reposição dos frutos. 

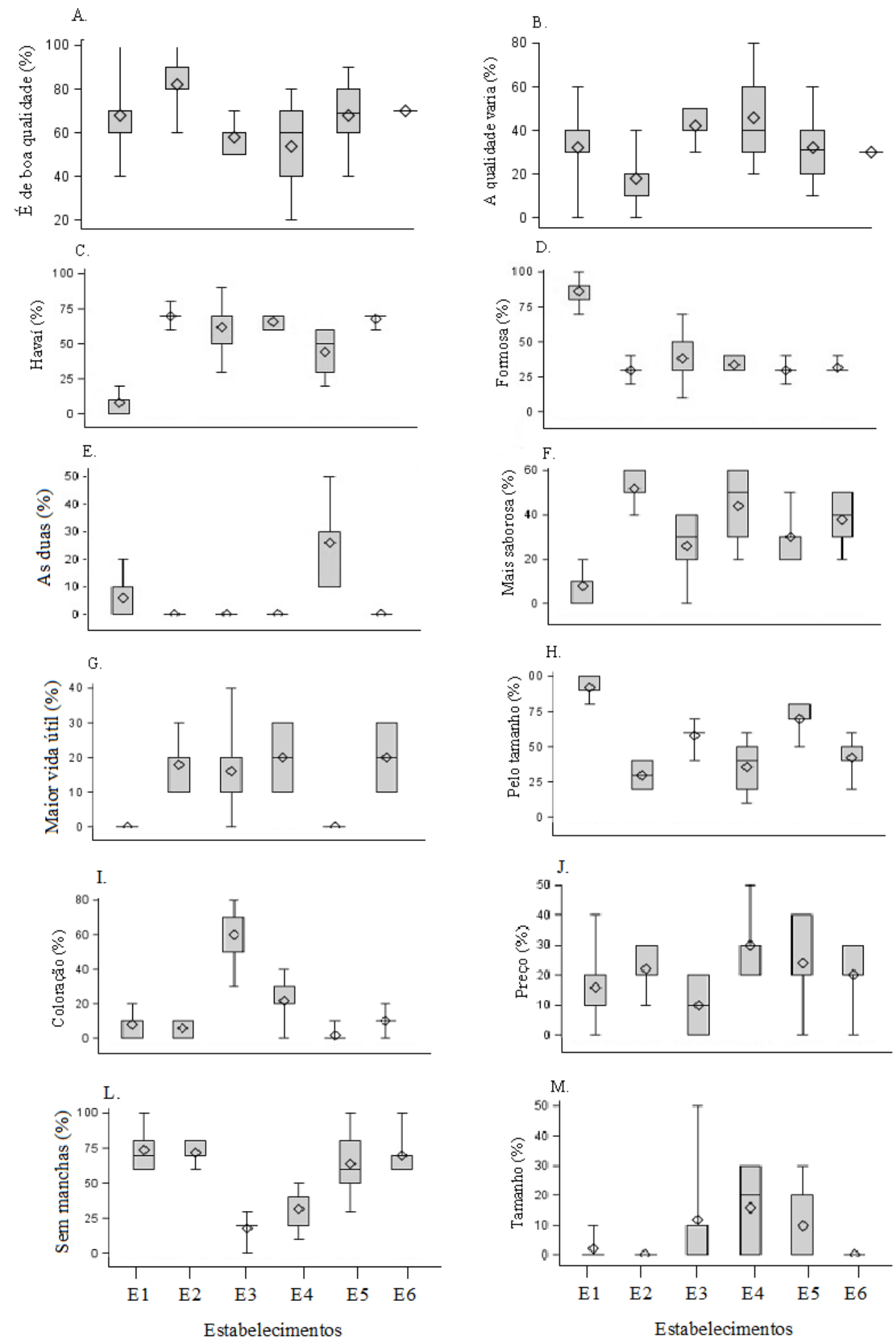

Figura 1 Box-Plot da percentagem de respostas sobre o que pensam a respeito da qualidade do mamão: é de boa qualidade (Figura 1A), a qualidade varia com a época do ano (Figura 1B); qual cultivar tem mais costume de comprar: Havaí (Figura 1C), Formosa (Figura 1D), as duas (Figura 1E); principal critério de preferência: mais saboroso (Figura 1F), maior vida útil (Figura 1G), pelo tamanho (Figura 1H); principal fator da escolha das cultivares: coloração (Figura 1I), preço (Figura 1J), sem manchas (Figura 1L), tamanho (Figura 1M), de mamão comercializadas no em diferentes supermercados na cidade de Campina Grande - PB, 2017 (Estabelecimentos E1, E3 e E4 de grande porte e E2, E5 e E6 de médio porte). 
O estabelecimento D disponibiliza 5 funcionários; $\quad$ o $\quad$ Estabelecimento $\quad$ B 2 funcionários; o $\mathrm{F} 4$ funcionários; o $\mathrm{E} \quad 6$ funcionários e o A 7 funcionários que diariamente realizam vistorias nos setores de hortifrutigranjeiro para retirada de frutos que estão fora do padrão de comercialização (feridos, doentes e machucados). A reposição de frutos no supermercado E6 é realizada todos os dias e nos demais 3 vezes por semana. Nas gôndolas, os frutos da mesma cultivar são expostos de forma aleatória sem seleção por maturação e peso, aumentando o manuseio pelos clientes.

As principais cultivares comercializadas são a Formosa e Havaí, havendo em cada supermercado uma clara preferência dos clientes por uma cultivar (Figura 1C, 1D, 1E). Nos supermercados E2, E3, E4 e E6 a cultivar Havaí é a mais procurada, com média de 70; 62; 66 e $68 \%$, respectivamente com base no tamanho. Por sua vez, mamão cv. Formosa é o preferido (86\%) pela grande maioria dos clientes do supermercado E1 (Figura 1D). Nos supermercados E1 e E5, para 16,66 e $9,94 \%$, respectivamente, dos clientes não há preferência (Figura 1E).

Os principais critérios de preferência de cultivares, na ordem, foram tamanho, vida útil e sabor (Figura H, F, G). Para o critério de escolha "sabor" os consumidores dos supermercados E2 (52\%) e E4 (44\%), com as maiores médias, seguidos do E6, E5, E3, E1 (38, 30, 26 e 8\%), o Havaí foi o mais citado como mais saboroso e com maior valor nutricional (Figura 1F). A maior vida útil foi citada pelos consumidores do E4, E6, E2 e E3, respectivamente, por 20, 20, 18, 16\% dos entrevistados (Figura 1G). No E1, a cv. Formosa é a mais comprada e o critério que mais influência o cliente é o tamanho do fruto (Figura $1 \mathrm{H}$ ), $92 \%$ dos entrevistados argumentaram que tinham famílias grandes e a minoria citaram que o preço era mais acessível. Foi possível observar que os consumidores preferiram a cv. Havaí por apresentar características de tamanho como um dos principais critérios de escolha, com o argumento de que por ser menor o fruto pode ser consumido no mesmo dia evitando desperdício e caso não seja consumido é mais prático para guardar, sendo apontada como opção de famílias pequenas ou quando poucas pessoas consomem.

Entre os principais fatores da escolha das cultivares (coloração, preço, sem manchas e tamanho), (Figura 1I, J, L, M) verificou-se que a coloração foi o mais apontado pelos consumidores do E3 (60\%) (Figura 1I). Como no E3 (estabelecimento de grande porte e maior poder aquisitivo) a preferência foi pela cv. Havaí, os clientes justificaram que por serem pequenos e por consumirem mais de uma vez na semana, compram mais de um fruto, baseado na coloração.

Segundo o gerente, o preço de venda do mamão é baseado na época do ano e no preço de aquisição, sendo o mesmo argumento apresentado nos estabelecimentos E3, E2, E6 e E5. O E1 se baseia na qualidade do fruto e na procura dos consumidores. Para Fagundes e Yamanishi (2002) a qualidade do mamão comercializado em Brasília dependia das condições climáticas, podendo ocorrer maior incidência de pragas e doenças em épocas chuvosas, reduzindo a produção, oferta e consequentemente, por conta da demanda dos produtos os preços de vendas aumentam e a qualidade tende a ser menor. Rangel et al. (2003) reportaram para consumidores de mamão dos grupos Solo e Formosa de Brasília, que os principais critérios que interferem na escolha é a ausência de defeitos (34,7\%), firmeza $(26,2 \%)$, coloração $(23,9 \%)$ e os principais problemas foram os danos físicos e presença de manchas.

A massa fresca de mamões cv. Formosa foi bem superior à Havaí, como esperado para esta característica varietal (Tabela 1). Entre os supermercados, a cv. Formosa, no E4 apresentou maior massa fresca $(1961,97 \mathrm{~g})$ e comprimento $(288,89 \mathrm{~mm})$ em relação aos demais. O mamão Havaí não diferiu quanto à massa fresca $\mathrm{e}$ comprimento entre supermercados.

Neste estudo, a massa média foi de 1573,12 e 514,60 g e comprimento médio de 26,34 e 13,86 $\mathrm{cm}$ para cv. Formosa e Havaí, respectivamente (Tabela 1). Fagundes e Yamanishi (2001) reportaram massa oscilando entre 372,2 a 537,1g e comprimento oscilou de 12,4 a $14,5 \mathrm{~cm}$ para cv. Solo, cujas variações foram relacionadas a fatores como: condições climáticas, tratos culturais, cultivar, época de plantio, colheita e outros. No geral, as variáveis estudadas enquadram o mamão no padrão aceitável para consumo fresco.

A percepção da coloração dos frutos diferiu entre supermercados e cultivares avaliadas. Numa escala de 0 a 10, notou-se, que nos estabelecimentos E1, E4 e E6, para a cv. Formosa 
comercializava frutos estavam regularmente uniformes com 6,18; 6,72 e 7,48, respectivamente, e para a cv. Havaí o E4 $(8,83)$ (Tabela 1). Dentre as cultivares, a coloração foi similar nos estabelecimentos E2 e E4. No E1, E3 e E5 a cv. Havaí apresentou maior uniformidade em relação à Formosa, e no E6 a Formosa foi mais similar (Tabela 1). Para o consumidor a variação de coloração é interessante, pois permite escolher o estádio de maturação dos frutos.
$\mathrm{O}$ atributo de qualidade brilho diferiu entre as cultivares nos supermercados E2, E3 e E6, e em todos os locais avaliados a cv. Formosa apresentou maior brilho em relação a Havaí. A presença de manchas escuras foi mais acentuada na cv. Havaí, com destaque para os supermercados E2 e E4, numa escala de 4,09 e 3,12 e para o cv. Formosa a maior ocorrência foi para o E2, E3 e E4, com 3,66; 3,64 e 3,53, respectivamente (Tabela 1 ).

Tabela 1 Massa fresca, Comprimento e atributos de qualidade sensorial em frutos de mamoeiro 'Formosa' e 'Havaí' comercializados em diferentes supermercados na cidade de Campina Grande-PB

\begin{tabular}{|c|c|c|c|c|c|c|}
\hline & E1 & E2 & E3 & E4 & E5 & E6 \\
\hline & \multicolumn{6}{|c|}{ Massa fresca $(\mathrm{g})$} \\
\hline \multirow{3}{*}{$\begin{array}{l}\text { Formosa } \\
\text { Havaí }\end{array}$} & $1393,87 \mathrm{bA}$ & $1428,64 \mathrm{bA}$ & $1502,09 \mathrm{bA}$ & $1961,97 \mathrm{aA}$ & $1598,76 \mathrm{bA}$ & $1553,39 \mathrm{bA}$ \\
\hline & $465,42 \mathrm{aB}$ & $499,59 \mathrm{aB}$ & $535,56 \mathrm{aB}$ & $511,78 \mathrm{aB}$ & $606,26 \mathrm{aB}$ & $469,01 \mathrm{aB}$ \\
\hline & \multicolumn{6}{|c|}{ Comprimento (mm) } \\
\hline Formosa & $264,72 \mathrm{bA}$ & $260,14 \mathrm{bA}$ & $262,69 \mathrm{bA}$ & $288,89 \mathrm{aA}$ & $249,03 \mathrm{bA}$ & $255,07 \mathrm{bA}$ \\
\hline \multirow[t]{2}{*}{ Havaí } & $135,74 \mathrm{aB}$ & $136,32 \mathrm{aB}$ & $138,12 \mathrm{aB}$ & $147,75 \mathrm{aB}$ & $142,81 \mathrm{aB}$ & $131,09 \mathrm{aB}$ \\
\hline & \multicolumn{6}{|c|}{ Uniformidade de cor } \\
\hline Formosa & $6,18 \mathrm{abcB}$ & $6,06 \mathrm{bcA}$ & $5,77 \mathrm{bcB}$ & $6,72 \mathrm{abB}$ & $5,10 \mathrm{cB}$ & $7,48 \mathrm{aA}$ \\
\hline \multirow[t]{2}{*}{ Havaí } & $7,36 \mathrm{bA}$ & $6,48 \mathrm{bA}$ & $7,14 \mathrm{bA}$ & $8,83 \mathrm{aB}$ & $6,42 \mathrm{bA}$ & $6,22 \mathrm{bB}$ \\
\hline & \multicolumn{6}{|c|}{ Brilho } \\
\hline Formosa & $6,27 \mathrm{abA}$ & $4,78 \mathrm{cA}$ & $6,53 \mathrm{abA}$ & $5,27 \mathrm{bcA}$ & $6,48 \mathrm{abA}$ & $7,22 \mathrm{aA}$ \\
\hline \multirow[t]{2}{*}{ Havaí } & $5,76 \mathrm{aA}$ & $3,20 \mathrm{bB}$ & $4,45 \mathrm{abB}$ & $4,92 \mathrm{aA}$ & $5,34 \mathrm{aA}$ & $4,78 \mathrm{aB}$ \\
\hline & \multicolumn{6}{|c|}{ Manchas escuras } \\
\hline Formosa & $2,76 \mathrm{abA}$ & $3,66 \mathrm{aA}$ & $3,64 \mathrm{aA}$ & $3,53 \mathrm{aA}$ & $2,24 \mathrm{abA}$ & $1,84 \mathrm{bA}$ \\
\hline \multirow[t]{2}{*}{ Havaí } & $2,00 \mathrm{bA}$ & $4,09 \mathrm{aA}$ & $1,92 \mathrm{bB}$ & $3,12 \mathrm{abA}$ & $2,38 \mathrm{bA}$ & $2,61 \mathrm{bA}$ \\
\hline & \multicolumn{6}{|c|}{ Desidratação } \\
\hline Formosa & $0,96 \mathrm{abA}$ & $1,99 \mathrm{aB}$ & $1,39 \mathrm{abA}$ & $1,82 \mathrm{abB}$ & $1,26 \mathrm{abA}$ & $0,67 \mathrm{bA}$ \\
\hline \multirow[t]{2}{*}{ Havaí } & $1,55 \mathrm{bA}$ & $3,17 \mathrm{aA}$ & $1,08 \mathrm{bA}$ & $2,85 \mathrm{aA}$ & $1,12 \mathrm{bA}$ & $1,38 \mathrm{bA}$ \\
\hline & \multicolumn{6}{|c|}{ Intenção de compra } \\
\hline Formosa & $7,03 \mathrm{bA}$ & $6,63 \mathrm{bA}$ & $7,55 \mathrm{abA}$ & $6,58 \mathrm{bA}$ & $7,67 \mathrm{abA}$ & $9,02 \mathrm{aA}$ \\
\hline Havaí & $7,57 \mathrm{abcA}$ & $6,10 \mathrm{cA}$ & $8,38 \mathrm{aA}$ & $6,71 \mathrm{bcA}$ & $7,68 \mathrm{abA}$ & $6,69 \mathrm{bcB}$ \\
\hline
\end{tabular}

*Médias seguidas de mesmas letras minúsculas nas linhas e maiúsculas nas colunas não diferem entre si pelo teste de Tukey e $\mathrm{F}$ respectivamente ao nível de 5\% de probabilidade de erro. Estabelecimentos E1, E3 e E4 de grande porte e E2, E5 e E6 de médio porte.

Em bananas, Leite et al. (2010) verificaram que a aparência em diferentes pontos de venda foi comprometida pelo transporte inadequado, presença de manchas e lesões nas cascas, danos profundos e podridões, manuseio excessivo. Vários fatores podem comprometer a aparência fruto, como o manejo inadequado da cultura até a colheita, transporte, embalagem e armazenamento. A aparência do fruto influencia na escolha do consumidor, sendo um fator de atratividade e fundamental na comercialização de frutos (Sivakumar e Wal, 2013).

A intenção de compra foi superior nos supermercados E3, E5 e E6 para a cv. Formosa, respectivamente 7,$55 ; 7,67$ e 9,02, e para a cv.
Havaí foram E1, E3 e E5, com 7,57; 8,38 e 7,68, respectivamente (Tabela 1). Notou-se que no geral clientes nos supermercados E4 (grande porte) e E2 (médio porte), da mesma rede, expressaram menores intenções de compras, devido ao preço.

Segundo os gerentes dos supermercados, os índices de perdas de mamão estão entre 5 a $10 \%$ nos E3 e E4, 11 a $15 \%$ no E2; E5 e E6 $\leq 4 \%$ e no E1 de 10 a $15 \%$. Para minimizar as perdas e manter a qualidade, o mamão nos supermercados de grande porte eram mantidos em câmaras com temperatura controlada (E1, E3 e E4). A forma de exposição dos mamões não variou em relação ao 
tipo de supermercados, sendo todos os frutos expostos em gôndolas.

O diâmetro dos frutos variou de 98,36 a 106,8 $\mathrm{mm}$ (Figura 2A), o que pode ter sido influenciado pelo local de origem. O supermercado E5 (médio porte) expunha frutos com maiores diâmetros que E1 (grande porte), não diferindo dos demais.
Entre as cultivares, a Formosa apresentou diâmetro de $116,87 \mathrm{~mm}$ e a cv. Havaí de 87,77 mm (Figura 2B). Em estabelecimentos de Brasília o diâmetro variou entre 78,6 a 92,1 mm para o grupo Solo (Fagundes e Yamanishi, 2001), entretanto Costa et al. (2011) reportaram menores médias (45 a $58 \mathrm{~mm}$ ) para mamão cv. Havaí da EMPASA de Campina Grande.
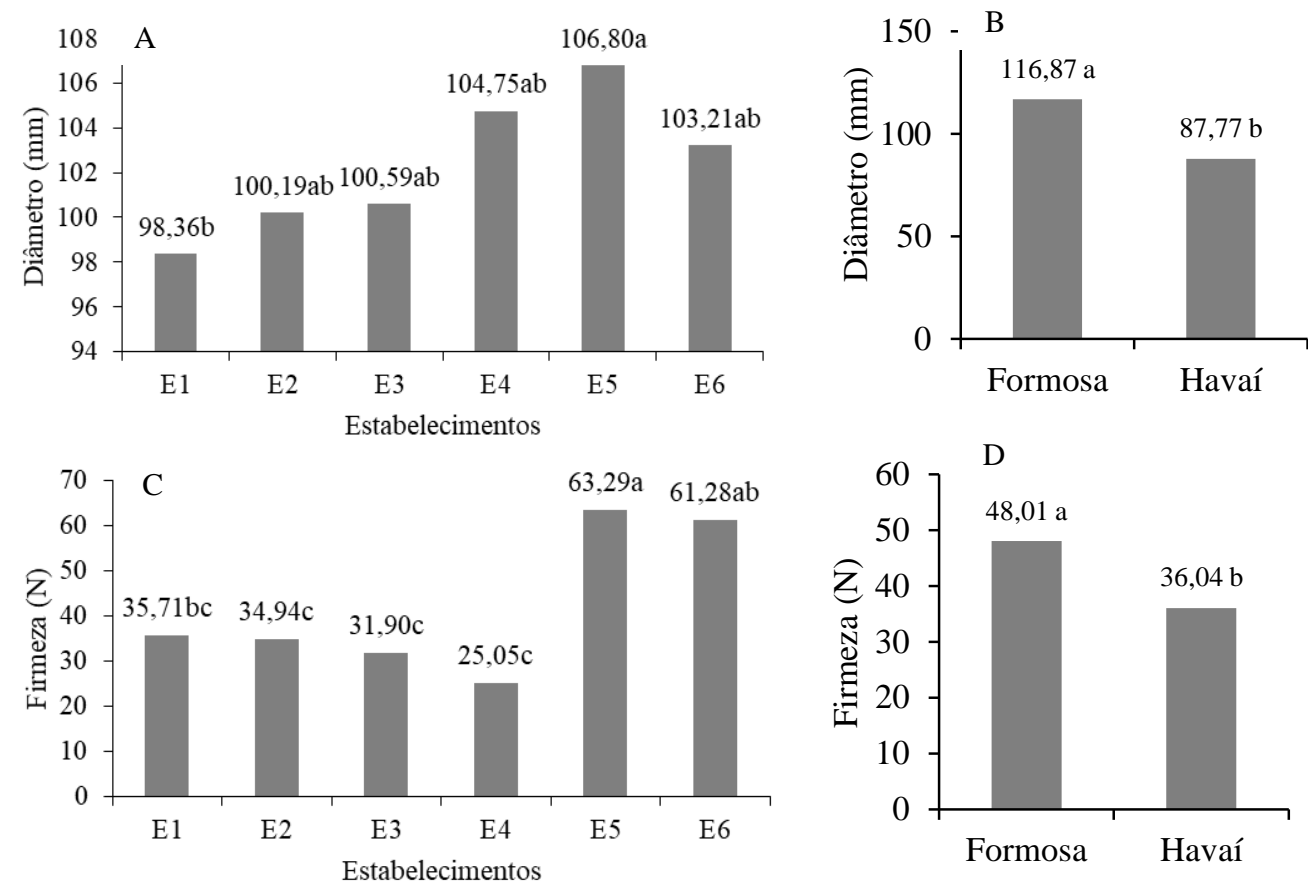

Figura 2 Diâmetro (A. e B.) e Firmeza (C. e D.) de frutos de mamoeiro 'Formosa' e 'Havaí' comercializados em supermercados E1, E2, E3, E4, E5 e E6, em Campina Grande-PB Areia-PB *Médias seguidas de mesma letra nas colunas para supermercados e variedades não diferem entre si pelo teste de Tukey e F respectivamente ao nível de $5 \%$ de probabilidade de erro. E1, E3 e E4 de grande porte e E2, E5 e E6 de médio porte.

Os supermercados E5 e E6 (médio porte) comercializavam mamão com maiores firmezas 63,29 e $61,28 \mathrm{~N}$, respectivamente, que no geral variou de 25,05 a 63,29 N (Figura 2C e D). Mamões Formosa eram mais firmes $(48,01 \mathrm{~N})$ do que os Havaí $(36,04 \mathrm{~N})$. A firmeza é um importante atributo na qualidade do mamão, porque afeta a sua resistência ao transporte e a susceptibilidade ao ataque de microrganismos $\mathrm{O}$ seu declínio, portanto, é um dos primeiros indicativos do amadurecimento, ocorrendo perda da integridade da parede celular devido à ação das enzimas pécticas, que solubilizam as protopectinas em pectinas ou ácido péctico, durante a maturação (Sivakumar e Wal, 2013).

A luminosidade $\left(\mathrm{L}^{*}\right)$ de mamões Formosa e Havaí foi maior na polpa do que na casca, com baixos valores de $a^{*}$ e elevados de $b^{*}$, em relação à polpa e a casca (Tabela 2), que caracterizam cor amarela da casca.

O teor de sólidos solúveis (Figura 4A) de mamões comercializados no período (verão) foi superior à média recomendada para colheita de frutos do grupo 'Sunrise-Solo' que é de 11,5\% (Fagundes e Yamanishi, 2001) e dentro da média para os o grupo 'Formosa' que é de 12,0\% (Oliveira et al., 2011). Durante a maturação de mamão o teor de açúcares aumenta, com o tipo, cultivar, condições climáticas, fertilidade do solo, época de produção, estádio de maturação. A acidez titulável (Figura 4B) variou entre 0,10 a $0,12 \mathrm{~g} \cdot 100 \mathrm{~g}^{-1} \mathrm{de}$ ácido cítrico, sendo próximos aos reportados por Dias et al. (2011), com 0,5 a $0,14 \mathrm{~g} \cdot 100 \mathrm{~g}^{-1}$ de ácido cítrico em frutos de diferentes genótipos de mamoeiro. Por sua vez, a 
relação SS/AT oscilou entre 128,40 e 108,81, diferindo entre cultivares (Figura 4C).

Para o parâmetro $a^{*}$, o estabelecimento E4 foi o que apresentou maior valor $(8,04)$, não diferindo do E2 (5,74), com cor levemente amarela, em detrimento aos supermercados E5, E6, E3 e E1 (Figura 3A e B).

Tabela 2 Luminosidade e parâmetro $a^{*}$ e $b^{*}$ de cor da casca de mamões 'Formosa' e 'Havaí' comercializados em diferentes supermercados da cidade de Campina Grande-PB

\begin{tabular}{lcccccc}
\hline & E1 & E2 & E3 & E4 & E5 & E6 \\
\hline Formosa & $40,30 \mathrm{abB}$ & $39,99 \mathrm{abB}$ & $39,47 \mathrm{abB}$ & $42,95 \mathrm{aB}$ & $39,60 \mathrm{abA}$ & $36,46 \mathrm{Bb}$ \\
Havaí & $46,80 \mathrm{abA}$ & $50,10 \mathrm{aA}$ & $48,20 \mathrm{Aa}$ & $50,81 \mathrm{aA}$ & $42,68 \mathrm{bA}$ & $47,83 \mathrm{aA}$ \\
\hline \multicolumn{7}{c}{$b^{*}$ da casca } \\
\hline Formosa & $43,56 \mathrm{ab}$ & $44,15 \mathrm{a}$ & $42,30 \mathrm{ab}$ & $44,87 \mathrm{a}$ & $42,45 \mathrm{ab}$ & $36,77 \mathrm{~b}$ \\
Havaí & $49,26 \mathrm{bc}$ & $54,63 \mathrm{ab}$ & $49,76 \mathrm{bc}$ & $57,59 \mathrm{a}$ & $46,56 \mathrm{c}$ & $51,25 \mathrm{abc}$ \\
\hline \multicolumn{7}{c}{$a^{*}$ da casca } \\
\hline Formosa & $28,11 \mathrm{aA}$ & $28,11 \mathrm{aA}$ & $27,68 \mathrm{aA}$ & $29,30 \mathrm{aA}$ & $27,06 \mathrm{aA}$ & $27,76 \mathrm{aA}$ \\
Havaí & $25,79 \mathrm{aB}$ & $24,67 \mathrm{abB}$ & $27,55 \mathrm{Aa}$ & $21,20 \mathrm{bB}$ & $25,34 \mathrm{aA}$ & $25,10 \mathrm{aB}$ \\
\hline
\end{tabular}

*Médias seguidas de mesmas letras minúsculas nas linhas e maiúsculas nas colunas não diferem entre si pelo teste de Tukey e F respectivamente ao nível de 5\% de probabilidade de erro. Estabelecimentos E1, E3 e E4 de grande porte e E2, E5 e E6 de médio porte
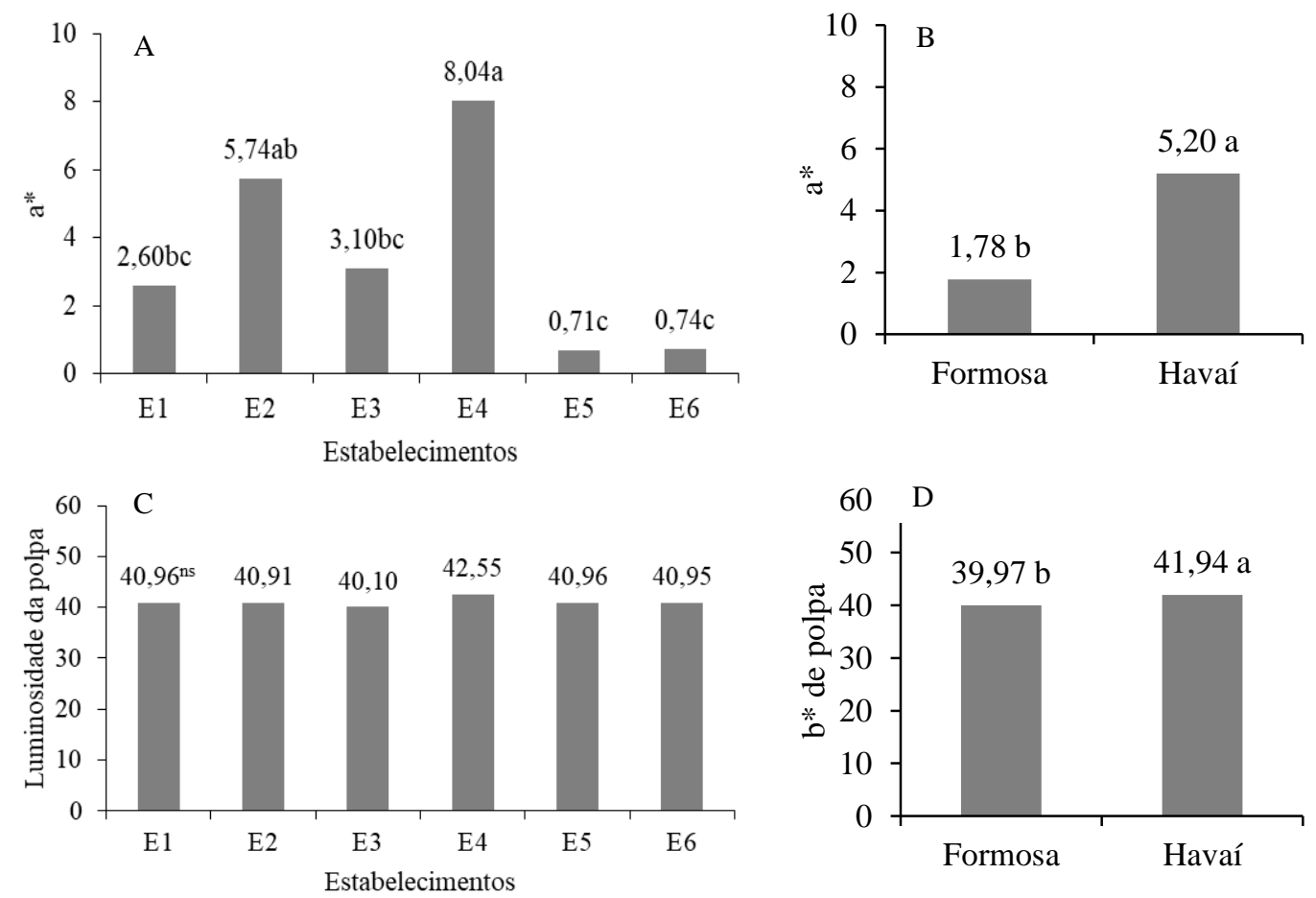

Figura 3 Parâmetro $a^{*}, b^{*}$ e $L^{*}$ de cor da casca de frutos de mamoeiro Formosa e Havaí comercializados em supermercados de Campina Grande-PB *Médias seguidas de mesma letra não diferem entre si pelo teste de Tukey e F respectivamente ao nível de 5\% de probabilidade de erro. E1, E3 e E4 de grande porte e E2, E5 e E6 de médio porte.

A aparência dos frutos é a combinação dos atributos geométricos e cromáticos e interfere diretamente na aceitabilidade destes pelos consumidores, que apresentam maior preferência por frutos com casca lisa e de coloração amarelo viva ou alaranjada brilhante em relação aos frutos de casca clara e esverdeada (Reis et al., 2015). O consumidor geralmente relaciona a coloração dos frutos com o aumento da doçura e com outros atributos desejáveis e por isso, na aquisição 
prefere os frutos mais coloridos (Rangel et al., 2003). No entanto, não é lucrativo para o comerciante colocar à venda frutos completamente maduros, pois estes são menos resistentes ao manuseio e apresentam pequena vida útil (Pan et al., 2017).

$\mathrm{O} \mathrm{pH}$ variou entre 5,12 e 5,48 (Figura 4D), estando próximos aos de Dias et al. (2011), 5,22 e 5,64 em mamões Formosa e Havaí, respectivamente. De acordo com Fagundes e Yamanishi (2002), o mamão 'Solo' apresenta pH entre 4,5 e 6,0. Assim, os mamões em Campina Grande- $\mathrm{PB}$, no período, apresentaram $\mathrm{pH}$ dentro do faixa de fruto para consumo fresco.
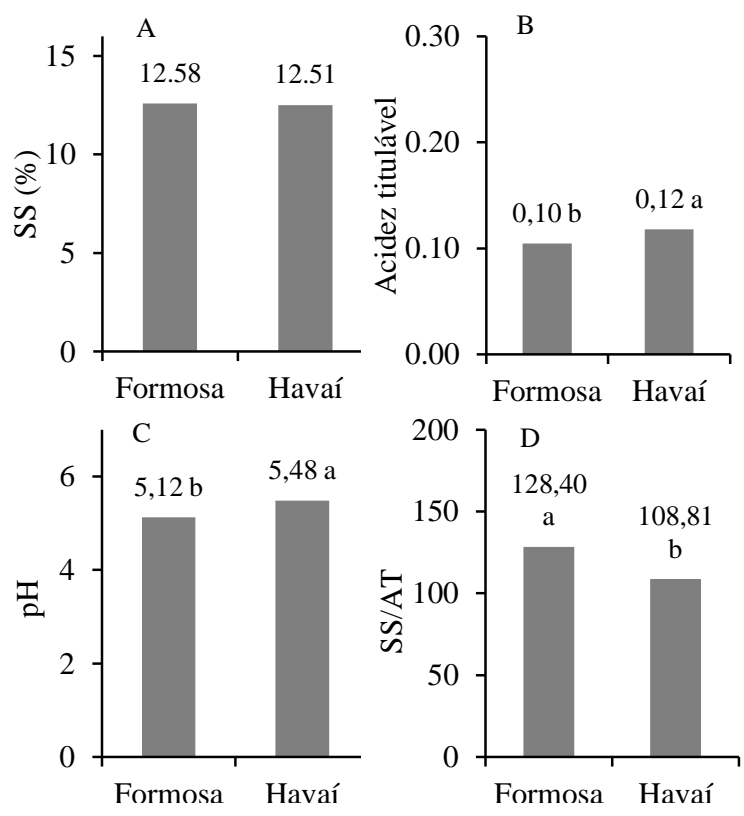

Figura 4 Conteúdo de Sólidos Solúveis - SS (A.), Acidez Titulável -AT (B.), potencial Hidrogeniônico (C.) e Relação SS/AT (D.) de frutos de mamoeiro 'Formosa' e 'Havaí' comercializados em Campina Grande-PB. Areia-PB *Médias seguidas de mesma letra não diferem entre si pelo teste $\mathrm{F}$ ao nível de 5\% de probabilidade de erro.

Para explicar satisfatoriamente a variabilidade entre os supermercados avaliados em Campina Grande em relação a cv. Formosa foram necessários dois componentes principais, com variância acumulada de 69,76\% (Figura 5A), sendo composta por $46,01 \%$ (CP1) e $23,75 \%$ (CP2). Para a CP1, as principais variáveis que explicaram a variabilidade entre os supermercados foram massa fresca, comprimento, sólidos solúveis, acidez titulável e a luminosidade da casca.
Para o CP2, as principais características foram diâmetro, firmeza, $\mathrm{pH}$, luminosidade da polpa. A partir de semelhanças dessas características, os supermercados foram reunidos em dois grupos (Figura 5B). Os mamões dos supermercados E1, E2, E3, E4 foram similares, principalmente, em relação à luminosidade da casca e polpa. Isso ocorreu provavelmente porque os estabelecimentos optam por adquirir frutos no início da maturação. Os supermercados E5 e E6 apresentaram mamões com maiores valores de diâmetro.

Para a cultivar Havaí, também foram necessários dois componentes principais para explicar a variabilidade entre os supermercados, com uma variância acumulada de $77,1 \%$ (Figura 5C), sendo 48,49\% (CP1) e 28,61\% (CP2). Para estabelecer as variáveis relacionadas com os componentes principais, com base nos autovetores, foi usado o critério de Jolliffe (1973). Em relação a CP1, as principais variáveis foram a luminosidade, $\mathrm{a}^{*}$ e $\mathrm{b}^{*}$ da casca e polpa e para CP2 foram comprimento, diâmetro e massa fresco. Os supermercados E1, E2, E3, E4 e E6 formaram um grupo e o E5 separou-se dos demais pela qualidade do fruto (Figura 5D).

A incidência de antracnose evoluiu independentemente da cultivar e do supermercado, acentuando-se a partir do $3^{\circ}$ dia ao ambiente (Figura 6A). A antracnose ocorre em maior frequência em frutos maduros (Tatagiba et al., 2002), portanto quanto maior o tempo de armazenamento maior a incidência da doença (Oliveira et al., 2011). O mamão Havaí foi mais afetado por antracnose, com maior severidade nos supermercados E1 e E4 (Figura 6B).

Durante cinco dias de armazenamento constatou-se que o mamão cv. Havaí foi mais susceptível à podridão peduncular, doença causada por um complexo de fungos (Nery-Silva et al., 2007), sendo que à evolução da doença no grupo Formosa praticamente não ocorreu independentemente do supermercado (Figura 6C). Em relação aos supermercados, mamões coletados no supermercado E4 apresentaram maior evolução da podridão peduncular, apresentando no $5^{\circ}$ dia de avaliação frutos com lesões coalescentes, aspecto translúcido ou mumificado, limitando-se à região peduncular, referente à nota 4 na escala utilizada. $\mathrm{O}$ supermercado com a $2^{\mathrm{a}}$ maior nota foi o E3, que no $5^{\circ}$ dia de avaliação, cujo mamão 'Havaí' 
apresentava lesões aquosas e mumificação, abrangendo grande parte da área em torno do
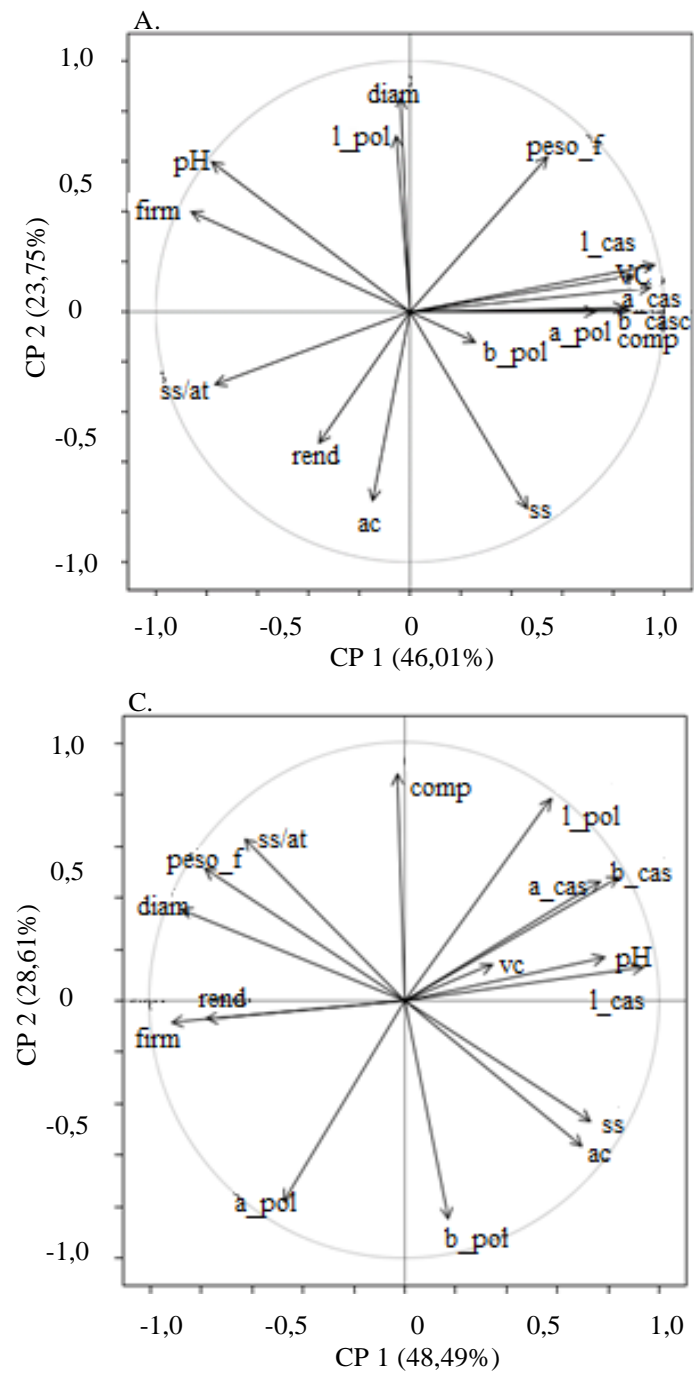

pedúnculo, caracterizando um estágio avançado desta doença (Oliveira et al., 2011).
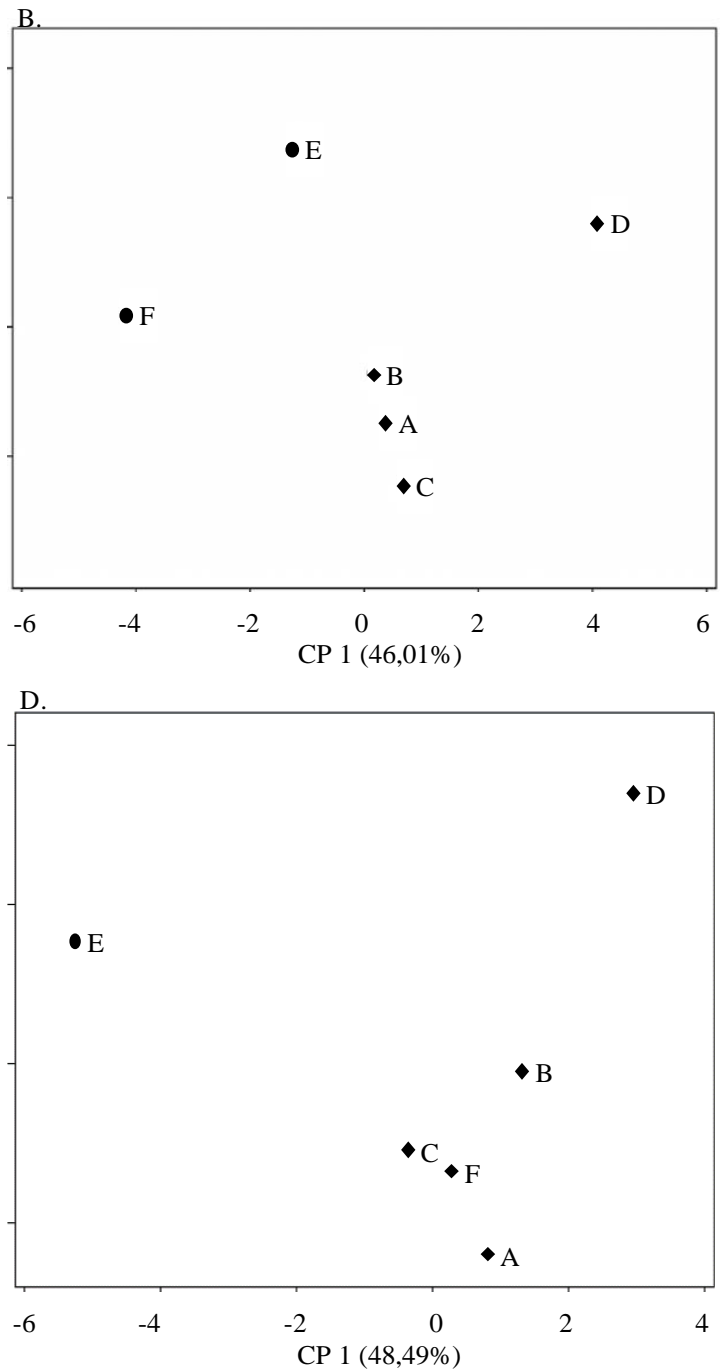

Figura 5 Círculos de autovetores das variáveis relacionadas às características físicas e físico-químicas e dispersão dos supermercados (E1 - E6) com base nos escores de dois componentes principais (CP1 e CP2) para os frutos de mamoeiro 'Formosa' (A. e B.) e Havaí (C. e D.) comercializados em diferentes supermercados da cidade de Campina Grande-PB.

Em relação à podridão peduncular os primeiros sintomas da doença foram observados após 24 horas de armazenamento, no primeiro dia de avaliação, para a cv. Havaí coletada no E4 e a partir do terceiro dia observou-se rápida evolução da doença (Figura 6C). No entanto, na cv. Formosa apenas no terceiro dia apareceram os sintomas iniciais da doença, pouco expressivos (Figura 6D). Gomes et al. (2010) ao avaliar a incidência natural da podridão peduncular causada por Lasiodiplodia theobromae em manga 'Tommy Atkins' comercializadas em Campina Grande, PB, observaram que os primeiros sintomas da doença surgiram no terceiro dia de armazenamento em mais de $50 \%$ dos frutos coletados.

$\mathrm{O}$ estabelecimento E2 foi o com menor evolução da podridão peduncular em frutos da cv. Havaí, apresentando em sua maioria ao final da avaliação frutos com ausências de sintomas da doença, mesmo os frutos estando no mesmo ambiente de vendas os frutos da cultivar Formosa apresentaram uma menor severidade na doença. 
Qualidade de frutos de cultivares de mamão comercializados em supermercados de ...

Barros et al.
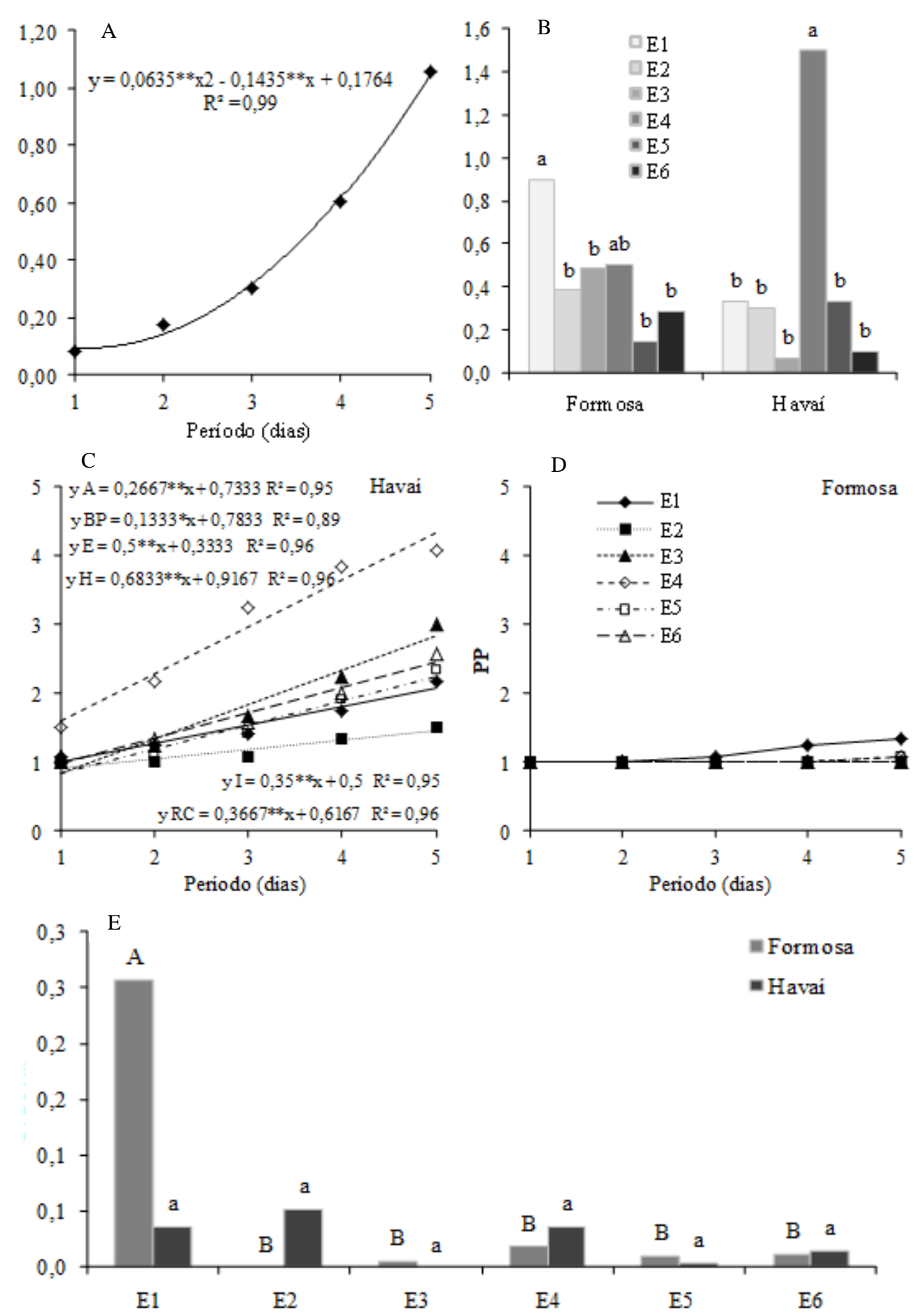

Figura 6 Incidência de antracnose (A e B), podridão peduncular (PP) (C e D) e da Pinta Preta (Asperisporium caricae) (E) em mamão Formosa e Havaí comercializados em diferentes supermercados da cidade de Campina Grande - PB durante cinco dias de armazenados ao ambiente, Areia-PB *Médias seguidas de mesma letra não diferem entre si pelo teste de Tukey ao nível de 5\% de probabilidade de erro. E1, E3 e E4 de grande porte e E2, E5 e E6 de médio porte.

A incidência da doença pinta preta, causada pelo patógeno (Asperisporium caricae), teve maior severidade nos mamões Formosa do supermercado E1, diferindo dos demais supermercados (Figura 6E). Isso indica problemas da doença nas áreas de produção, já que as doenças provêm do campo (Prusky, 2011).

Frutos cv. Havaí apresentaram baixa ou nenhuma incidência de pinta preta, com destaque 
para o supermercado E3, onde não se observou nenhum fruto contaminado. A presença de um sintoma de doença em frutos já o desqualifica para a comercialização, necessitando de tratamento preventivo no campo visando a obtenção de frutos sem doenças, com uma maior qualidade (Dantas et al., 2003).

\section{Conclusão}

O mamão Havaí é o preferido pelos clientes, com base no tamanho. Em geral, a qualidade de frutos foi apontada como superior pelos clientes nos supermercados de médio porte, em contraste dos de grande porte;

A logística de compra, venda e transporte foram apontados pelos supermercados como fatores limitantes na manutenção da qualidade. Os supermercados de grande porte apontam a manipulação dos frutos pelos clientes como fator mais crítico para a perda da qualidade;

As manchas pretas foram mais acentuadas em mamão Havaí, principalmente os supermercados E2 (médio porte) e E4 (grande porte), da mesma rede. Para a podridão peduncular, mamões cv. Havaí foram também os mais afetados. Para a pinta preta, o supermercado E1 apresentou maior severidade da doença no mamão Formosa.

\section{Referências}

AOAC - Association of Official Analytical Chemistry. Official methods of analysis of the Association of Official Analytical Chemistry. $17^{\mathrm{a}}$ Ed. Washington: AOAC, 2005. 1115p.

Aujla, K. M. Shah, N. A.; Ishaq, M.; Fraooq, A. Post-harvest losses and marketing of grapes in Pakistan. Sarhad Journal of Agriculture, v.27, n.3, p.485-490, 2011. http://www.aup.edu.pk/si pdf/harvest\%20losses\%20and. PDF

Costa, L. C. Ribeiro, W. S.; Almeida, E. I. B.; Gurjão, G. C.; Barbosa, J. A. Procedência, qualidade e perdas pós-colheita de mamão 'Havaí' no mercado atacadista da EMPASA de Campina Grande-PB. Revista Agropecuária Técnica, v.32, n.1, p.21-34, 2011. https://doi.org/10.25066/agrotec.v32i1.7207

Dantas, S. A. F.; Oliveira, S. M. A.; Michereff, S. J.; Nascimento, L. C.; Gurgel, L. M. S.; Pessoa, W. R. L. S. Doenças fúngicas pós-colheita em mamões e laranjas comercializados na Central de Abastecimento do Recife. Fitopatologia
Brasileira, v.28, n.5, p.528-533, 2003. http://dx.doi.org/10.1590/S0100-41582003000500010

Dias, N. L. P.; Oliveira, E. J.; Dantas, J. L. L. Avaliação de genótipos de mamoeiro com uso de descritores agronômicos e estimação de parâmetros genéticos. Pesquisa Agropecuária Brasileira, v.46, n.11, p.1471-1479, 2011. http://dx.doi.org/10.1590/S0100-204X2011001100008

Fagundes, G. R.; Yamanishi, O. K. Características físicas e químicas de frutos de mamoeiro do grupo 'Solo' comercializados em 4 estabelecimentos de Brasília - DF. Revista Brasileira de Fruticultura, v.23, n.3, p.541545, 2001. http://dx.doi.org/10.1590/S010029452001000300018

Fagundes, G. R.; Yamanishi, O. K. Estudo da comercialização do mamão em Brasília-DF. Revista Brasileira de Fruticultura, v. 24, n. 1, p. 091-095, 2002. http://dx.doi.org/10.1590//010029452002000100020

Food and Agriculture Organization of The United Nations. FAO - Food and Agriculture Organization of the United Nations. Disponível em: < http://www.fao.org.br > Acesso em: 29 Abr. 2018.

Gomes, C. E. S.; Gondim, P. J. S.; Santos, M. F. G.; Nascimento, L. C.; Batista, J. L.; Silva, S. M. Podridão peduncular e qualidade de mangas' Tommy atkins' procedentes do mercado atacadista de Campina Grande-PB. Revista Brasileira Fruticultura, v.32, n.4, p.12671271, 2010. http://dx.doi.org/10.1590/S010029452010005000133

Instituto Brasileiro de Geografia e Estatística. Produção Agrícola Municipal. Disponível em: < http://www.ibge.gov.br >. Acesso em: 20 Abr. 2017.

Jolliffe, I. T. Discarding variables in a principal components analysis. I. Real data. Applied Statistics. Journal of the Royal Statistical Society Series, v.21, n.2, p.160-173, 1973. http://dx.doi.org/10.2307/2346300

Leite, G. A.; Medeiros, E. V.; Mendonça, V.; Moraes, P. L. D.; Lima, L. M.; Xavier, I. F. Qualidade pós-colheita da banana 'Pacovan' comercializada em diferentes estabelecimentos no município de Mossoró-RN. Revista Brasileira de Ciências Agrárias, v.5, n.3, p.322-327, 2010. http://dx.doi.org/10.5039/agraria.v5i3a614 
Nery-Silva, F. A.; Machado, J. C.; Resende, M. L. V.; Lima, L. C. O. Metodologia de inoculação de fungos causadores da podridão peduncular em mamão. Ciência e Agrotecnologia, v.31, n.5, p.1374-1379, 2007. http://dx.doi.org/10.1590/S1413-70542007000500015

Oliveira, A. A. R.; Santos Filho, H. P.; Andrade, E. C.; Meissner Filho, P. E. Impacto potencial das mudanças climáticas sobre as doenças do mamoeiro no Brasil. In: Ghini, R.; Hamada, E.; Bettiol, W. (Editores). Impactos das mudanças climáticas sobre doenças de importantes culturas no Brasil. Jaguariúna: Embrapa Meio Ambiente, 2011. p. 356.

Pan, Y. G. Yuan, M. Q.; Zhang, W. M.; Zhang, Z. $\mathrm{K}$. Effect of low temperatures on chilling injury in relation to energy status in papaya fruit during storage. Postharvest Biology and Technology, v.125, p.181-187, 2017. https://doi.org/10.1016/j.postharvbio.2016.11.016

Parfitt, J.; Barthel, M.; Macnaughton, S. Food Waste Within Food supply chains: quantification and potential for change to 2050 . Philosophical Transactions of The Royal Society, v.365, n.1554, p.3065-3081, 2010. http://dx.doi.org/10.1098/rstb.2010.0126

Prasad, K.; Jacob, S.; Siddiqui, M W. Fruit Maturity, Harvesting, and Quality Standards. Preharvest Modulation of Postharvest Fruit and Vegetable Quality, p. 41-69, 2018. https://doi.org/10.1016/B978-0-12-809807-3.00002-0

Prusky, D. Reduction of the incidence of postharvest quality losses, and future prospects. Food Security, v.3, n.4, p.463-474, 2011. https://doi.org/10.1007/s12571-011-0147-y
Rangel, S. B.; Fagundes, G. R.; Falcão, T. C. C.; Mendes, R. S.; Yamanishi, O. K. Perfil do mercado varejista e consumidor de mamão dos grupos 'solo' Solo' e 'formosa' Formosa' do Distrito Federal - DF. Revista Brasileira de Fruticultura, v.25, n.1, p.85-88, 2003. http://dx.doi.org/10.1590/S0100-29452003000100025

Reis, R. C. Viana, E. S.; Jesus, J. L.; Dantas, J. L. L.; Lucena, R. S. Caracterização físico-química de frutos de novos híbridos e linhagens de mamoeiro. Pesquisa Agropecuária Brasileira, v.50, n.3, p.210-217, 2015. http://dx.doi.org/10.1590/S0100-204X2015000300004

Rupasinghe, H. P. V.; Yu, L. J. Value-Added Fruit Processing for Human Health. In: Food Industry. Intech: Open Science, 2013. Cap. 7, p.145-172. https://dx.doi.org/10.5772/53161

Tatagiba, J. S. Liberato, J. R.; Zambolim, L.; Ventura, J. A.; Costa, H. Controle e condições climáticas favoráveis à antracnose do mamoeiro. Fitopatologia Brasileira, v. 27, n. 2, p.186-192, 2002. http://dx.doi.org/10.1590/S010041582002000200011

Sivakumar, D.; Wal, M. M. Papaya Fruit Quality Management during the Postharvest Supply Chain. Food Reviews International, v.29, n.1, p.24-48,

2013. https://doi.org/10.1080/87559129.2012.692138

Vivas, M. Terra, C. E. P. S.; Silveira, S. F.; Fontes, R. V.; Pereira, M. G. Escala diagramática para avaliação da severidade de pinta-preta em frutos de mamoeiro. Summa Phytopathologica, v.36, n.2, p.161-163, 2010. http://dx.doi.org/10.1590/S0100-54052010000200010 